\title{
Respiratory physiotherapy in patients with COVID-19 infection in acute setting: a Position Paper of the Italian Association of Respiratory Physiotherapists (ARIR)
}

\author{
Marta Lazzeri ${ }^{1,2}$, Andrea Lanza ${ }^{2,3}$, Raffaella Bellini ${ }^{2,4}$, Angela Bellofiore ${ }^{2,5}$, Simone Cecchetto ${ }^{6,7}$, \\ Alessia Colombo ${ }^{2,5}$, Francesco D'Abrosca ${ }^{2}$, Cesare Del Monaco ${ }^{8}$, Giuseppe Gaudiello ${ }^{2}$, Mara Paneroni ${ }^{2,9}$, \\ Emilia Privitera $^{2,5}$, Mariangela Retucci ${ }^{8}$, Veronica Rossi ${ }^{5}$, Martina Santambrogio ${ }^{2,8}$, \\ Maurizio Sommariva ${ }^{10}$, Pamela Frigerio ${ }^{11}$
}

${ }^{1}$ Department of Cardiothoracic and Vascular Surgery, ASST Grande Ospedale Metropolitano Niguarda, Milan; ${ }^{2}$ Italian Association of Respiratory Physiotherapists (ARIR), Unità Spinale ASST Grande Ospedale Metropolitano Niguarda, Milan; ${ }^{3}$ Department of Neuroscience, Sleep Medicine Center, ASST Grande Ospedale Metropolitano Niguarda, Milan; ${ }^{4}$ Department of Rehabilitation, Azienda Ospedaliera Universitaria Integrata, Verona; ${ }^{5}$ Health Professions Department Unit, Fondazione Cà Granda Ospedale Maggiore Policlinico, Milan; ${ }^{6}$ Italian Association of Physiotherapists, Rome; ${ }^{7}$ Direction of Health Professions, APSS Trento; ${ }^{8}$ Respiratory Unit and Adult Cystic Fibrosis Center, Fondazione IRCCS Cà Granda Ospedale Maggiore Policlinico, Milan; ${ }^{9}$ Respiratory Rehabilitation Departement, ICS Maugeri, Lumezzane (BS); ${ }^{10}$ Emergency Department, ASST Grande Ospedale Metropolitano Niguarda, Milan; ${ }^{11}$ Maternal and Pediatric Department, ASST Grande Ospedale Metropolitano Niguarda, Milan, Italy

\section{Introduction}

On February 2020, Italy, especially the northern regions, was hit by an epidemic of the new SARS-Cov-2 coronavirus that spread from China between December 2019 and January 2020 [1].

The entire healthcare system had to respond promptly in a very short time to an exponential growth of the number of subjects affected by COVID-19 (Coronavirus disease 2019) with the need of semi-intensive and intensive care units.

In these regions, hospitals entire buildings and wards have been converted in semi-intensive and intensive care units and trained dedicated COVID-19 teams consisting of physicians (intensivists or pneumologists or other trained specialists as well as infectiologists and nurses have been recruited to work on and on with rest.

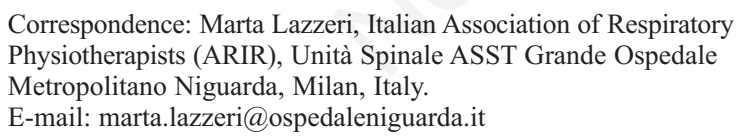

Key words: Coronavirus; COVID-19; SARS-Cov-2; infection; physiotherapy; rehabilitation.

Acknowledgments: We are very grateful to Prof. Thierry Troostersor for his help, advices, and support.

Received for publication: 24 March 2020.

Accepted for publication: 25 March 2020.

${ }^{\circ}$ Copyright: the Author(s), 2020

Licensee PAGEPress, Italy

Monaldi Archives for Chest Disease 2020; 90:1285

doi: 10.4081/monaldi.2020.1285

This article is distributed under the terms of the Creative Commons Attribution Noncommercial License (by-nc 4.0) which permits any noncommercial use, distribution, and reproduction in any medium, provided the original author(s) and source are credited.
Physiotherapists, mainly respiratory physiotherapists, are among the healthcare professionals involved in the management and care of these patient's population and play a key role in the non-invasive support management, postural changes, mobilization, as well as during the weaning from invasive mechanical ventilator support.

This document was drafted by ARIR (Italian Association of Respiratory Physiotherapists) in collaboration with AIFI (Italian Association of Physiotherapist) in order to support the work of the worldwide colleagues dealing with the COVID-19 emergency.

The presentation of this manuscript is the result of a consensus between Italian physiotherapists with specific expertise in respiratory care, working with COVID-19 patients in the hospitals of the north of Italy. Therefore, our aim is to share information with worldwide physiotherapists involved in the management of patients affected by COVID-19. Considering the complexity and frailty of COVID-19 patients, we recommend, when possible, to have as a task force, physiotherapists with expertise and/or dedicated training in Respiratory Physiotherapy (RT).

Therapists who read this article should adjust or modify the procedures described in this document and in other official guidelines to their specific clinical setting.

Considering the fast and continuous evolution of the epidemiological framework, indications included in this document are not prescriptive, should ALWAYS be adapted to the guidelines coming from the "Crisis Unit", and approved by Directors of Institutes that manage COVID-19 patients, in the specific professional working environment of each hospital. Furthermore, it is anticipated that these guidelines will need further updates as further evidence on treatment approaches will become available in the near future.

Italian Physiotherapists Experience with SARS-Cov-2 Patients

Patients affected by coronavirus disease (SARS-Cov-2) may develop pneumonia characterized by bilateral interstitial infiltrates, with severe hypoxic respiratory failure (ARDS - Acute 
Respiratory Distress Syndrome). Indeed, this can cause serious alterations of the ventilation-perfusion ratio with possible shunt [2].

The acute hypoxemic patients may experience dyspnoea that may persist despite the administration of oxygen flows $>10-15$ $\mathrm{L} /$ min with a reservoir mask [3]. In these cases, other devices, such as High-Flow Nasal Oxygen (HFNO) or the application of Continuous Positive Airways Pressure (CPAP) or Non-Invasive Ventilation (NIV) may be useful. However, it is important to point out that these interventions have to be used only in appropriate hospital settings in order to be prepared for a more aggressive treatment.

A potential rapid worsening of hypoxemia with subsequent need of intubation and invasive mechanical ventilation has to be taken in account in patients with SARS-Cov-2. Considering the risk of NIV failure, it is necessary to manage these patients with immediate availability of a staff able to perform endotracheal intubation [4]. In our preliminary experience, the percentage of failure of CPAP/NIV is extremely high.

When indicated, the administration of CPAP/NIV can be carried out with various interfaces, depending on the availability and indications (oro-nasal mask, total face or helmet). When using $\mathrm{CPAP} / \mathrm{NIV}$, it is important to consider the potential environmental diffusion of aerosol particles of the virus [5]. In particular, one of the critical issues of the SARS-Cov-2 in the intermediate phase (between the onset of disease and potential critical evolution, also in relation to comorbidity) is represented by the selection of oxygen therapy and the level of care. Non-invasive supports (CPAP, NIV and HFNO) can correct hypoxemia and respiratory failure (even in the absence of clear evidence from proper randomized controlled studies), delaying or avoiding endotracheal intubation (and its potential complications and effects on the outcome) [6]. However, looking at SARS epidemic data, physiotherapists have to be careful when treating these patients because there is evidence that NIV may increase the risk of aerial spreading of the virus [5]. Thus, if a patient shows prognostic factors suggesting the need of invasive ventilation [7], it is preferable to carry out elective intubation, rather than emergency intubation in critical conditions. This action will allow minimizing complications of intubation itself for the patient, as well as reducing the risk of contamination due to potential errors in Protective Personal Equipment (PPE) usage of the healthcare personnel.

To date, there are no clear recommendations for the use of NIV in case of de-novo hypoxic acute respiratory failure or specifically hypoxemia associated with viral pneumonia. The delay in endotracheal intubation by prolonged use of NIV is associated with higher mortality rate, especially in the more severe cases [6-7].

\section{1st ADVICE:}

Consider the high risk of failure of non-invasive management and monitor carefully for potential sudden clinical deterioration.

Do not persist with non-invasive treatments, if the patient does not quickly respond to the treatment. Alert the team and prepare for invasive mechanical ventilation sooner rather than later!

\section{$2^{\text {nd }}$ ADVICE:}

It is appropriate to adopt shared strategies performed by a multidisciplinary team, taking into account the levels of care available, the equipment accessible and the feasibility of intensive assistance in dedicated settings.

\section{Best Practice Recommendations for Spontaneously Breathing Patients or with Non-Invasive Ventilatory Support (NIV)}

Conventional oxygen therapy: It is not recommended to use nasal cannulas, which may cause a higher dispersion of droplets than other systems. We recommend using a facemask with an oxygen flow up to $5 \mathrm{~L} / \mathrm{min}$, a reservoir mask up to $10 \mathrm{~L} / \mathrm{min}$ of $\mathrm{O}_{2}$ or a Venturi mask up to $60 \%$ of $\mathrm{FiO}_{2}$. We also suggest the addition of a surgical mask covering the patient face where more dispersion of droplets can be observed. It has to be correctly positioned and it has to be changed every 6-8 hours [8-11].

High Flow Nasal Oxygen (HFNO): we suggest the use of a flow of at least $50 \mathrm{~L} / \mathrm{min}$ and $\mathrm{FiO}_{2}$ up to $60 \%$. The nasal cannula must be well-positioned inside the nostrils and a surgical mask should be added over the nasal cannulas covering patient' mouth and nose as with the conventional oxygen therapy. The surgical mask has to be changed at least every 6 to 8 hours $[12,13]$.

For subjects who adopt an open-mouth breathing pattern, a non-vented NIV mask connected by T-tube to the circuit can be used in order to improve oxygen saturation $\left(\mathrm{SpO}_{2}\right)$ (Figure 1).

Continuous Positive Airway Pressure/ Non-Invasive ventilation (CPAP/NIV): We suggest making a single attempt of noninvasive support for a maximum duration of 1 hour. If no substantial improvement is observed, notify the team and switch to the appropriate (invasive ventilatory) support [6-7].

Interface: to minimize the risk of nebulization of infected material, the safest interface is the helmet, which is relatively closed to the environment in comparison with a mask. Also, as the helmet acts as a reservoir, the addition of antiviral filters to the expiratory port in order to decrease the droplets, may produce less

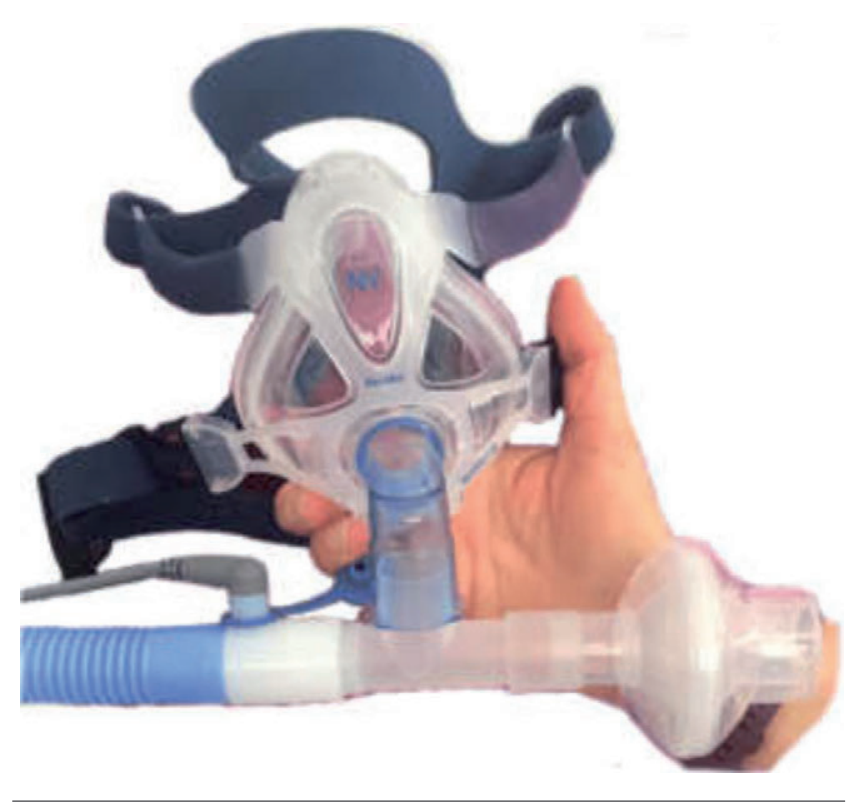

Figure 1. Setting of a HFNO circuit for patients who adopt an open-mouth breathing pattern. 
resistance to the patient breathing effort in comparison to a mask. When using a face mask, the best choice is to combine it with a double circuit with an expiratory valve. In the case there is need to combine a face mask with a single circuit, we suggest to use a circuit equipped with an integrated exhalation port instead of using vented masks. In addition, an antimicrobial and antiviral filter should always be installed [12]. An example of the mentioned circuit is described in Figure 2.

Antimicrobial filters: We highly recommend to verify the filter placement according to the ventilation setting and to the PPE available for the staff. Filters should be positioned to limit the dispersion of the exhaled air into the surrounding environment. The placement of double filters can alter the pressure in the circuit used for ventilation. Therefore, daily external monitoring of the pressure by manometers is recommended.

Posture changes: The posture assumed by the patients is crucial in this context. We recommend favouring an extended semisitting or sitting position avoiding a slumped position. When possible and in close collaboration with the team, favour alternations of the lateral decubitus, consider whether the semi-prone or prone position might be indicated [6]. It is necessary to minimize the patient effort even in maintaining postures. Hence, it is recommended to use cushions/aids that allow a stable position without active muscles work from the patient.

\section{$3^{\text {rd }}$ ADVICE}

In spontaneously breathing patients, the changes of position can modify the ventilation/perfusion ratio and may lead to a sudden change (improvement or deterioration) of gas exchange.

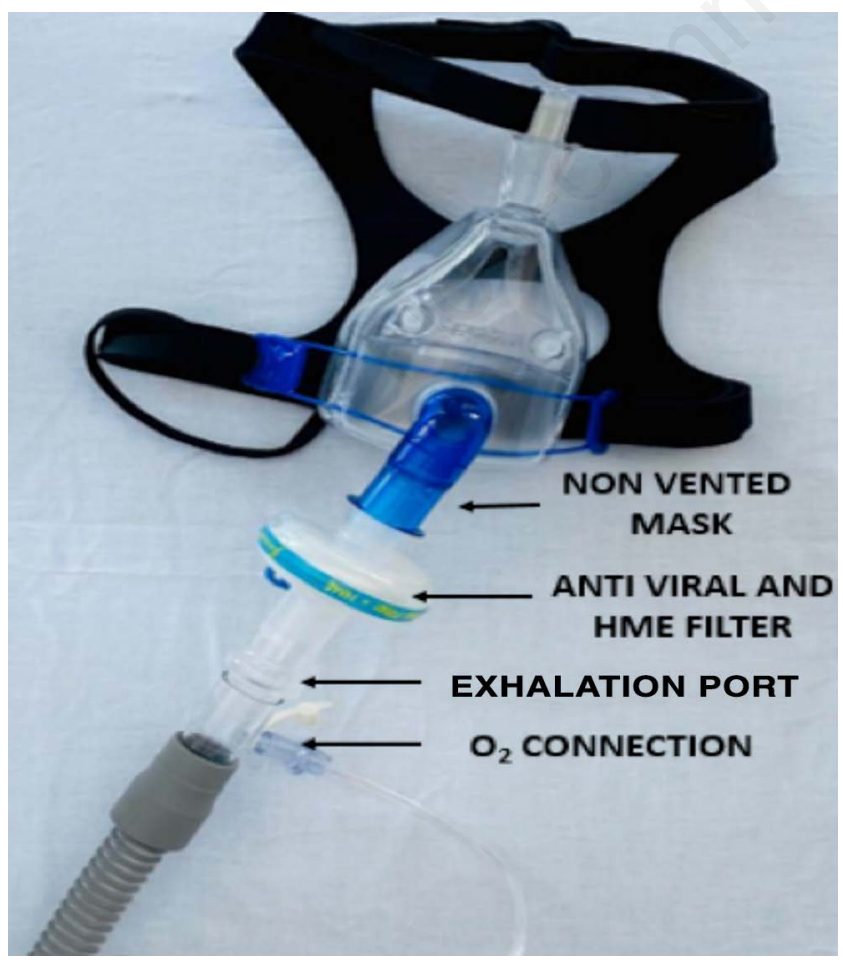

Figure 2. Setting of a circuit of a single-tube CPAP with exhalation port and with non-vented mask.
Careful evaluation and clinical and instrumental monitoring of the patient are therefore required after a postural change.

\section{Recommendations for Patients in Invasive Mechanical Ventilation}

In order to reduce droplets dispersion during the management of patients in invasive mechanical ventilation, we recommend: a) periodical verification of the pressure in the endotracheal cuff (25$30 \mathrm{~cm} \mathrm{H}_{2} \mathrm{O}$ ); and b) to avoid delivering of inhaled therapy using a pneumatic jet nebulizer. A preferred option is to use dry inhalers or ultrasonic nebulizers connected to the mechanical ventilator in a closed circuit, without removing the antimicrobial filter on the expiratory branch of the circuit.

Airway clearance techniques: Since airway clearance causes massive droplet dispersion, airway clearance procedures should be administered only when considered strictly needed for the clinical improvement of the patient. To date, in our experience, airway clearance is not frequently required in COVID-19 patients.

Lung recruitment manoeuvres: These manoeuvres may be indicated in certain clinical circumstances, but they could be considered dangerous [14] and must be shared by the team.

Endotracheal suction: we do not recommend disconnections from the ventilator, in order avoid loss of Positive End Expiratory Pressure (PEEP) and atelectasis worsening. Therefore, we recommend to use close suction circuit [15]. Close circuit usage could also decrease the risk of droplets spreading. Bronchial suction manoeuvres should be performed only on strict indications.

Changes in posture: The prone position is recommended at least for 12 to 16 hours per day, preferably within 72 hours of endotracheal intubation. If these positions have been effective, repeat them until $\mathrm{PaO}_{2} / \mathrm{FiO}_{2}$ ratio $(\mathrm{P} / \mathrm{F}) \geq 150 \mathrm{mmHg}$ with $\mathrm{PEEP}$ $\leq 10 \mathrm{cmH}_{2} \mathrm{O}$ and $\mathrm{FiO} 2 \leq 0.60$ for at least 4 hours after supine position. The pronation procedure must be interrupted in case of oxygenation worsening ( $20 \%$ decrease in $\mathrm{P} / \mathrm{F}$ compared to the supine position) or in case of serious complications [16].

Some suggestions to avoid side effects of prone position are described in Table 1.

\section{$5^{\text {th }}$ ADVICE}

Reduce unnecessary manoeuvres, particularly procedures that can generate PEEP reduction with a subsequent increased risk of lung de-recruitment and atelectasis.

\section{$6^{\text {th }}$ ADVICE}

Application of prone position during ventilation requires sufficient human resources and expertise to be performed safely.

It is very important to verify that prolonged prone position during ventilation does not cause side effects.

Prevention of complications: It is important to alert the staff in the prevention of the following side effects/ complications:

a) Difficult weaning: It is necessary to implement daily assessment of spontaneous breathing ability. It should be done following dedicated protocols [17].

b) Ventilator-associated pneumonia (VAP). To avoid VAP, we suggest to: i) keep the patient in a semi-sitting position (30$\left.45^{\circ}\right)$; ii) to use a closed tracheal-suction system; iii) to use a new ventilator circuit for each patient, and once the patient is 
ventilated pay attention to change the circuit only when it is damaged [18].

- Venous thromboembolism

- Pressure ulcers

- Critical Illness Myopathy and Neuropathy (CRIMYNE) and physical disability. To avoid it, the best practice is to promote early patient mobilization as soon as disease course conditions allow it (clinical stability). It may be useful to use dedicated protocol [19-21].

\section{$7^{\text {th }}$ ADVICE}

Passive mobilization should be considered in order to prevent skin lesions and immobilization sequelae. Discuss with the team the possibility to start an early active mobilization program as soon as patient'sedation is reduced.

\section{Procedures NOT to be applied in the Acute Phase}

In the presence of acute respiratory failure that determines a reduction of lung compliance, the increase of respiratory work of breathing and alteration of blood oxygenation leads to a rapid and shallow respiratory pattern [2]. this pattern is usually spontaneously adopted by the subject representing a strategy to minimize inspiratory effort and maximize mechanical efficiency of breathing. Furthermore, in such clinical conditions, the strength of the respiratory muscles can also be reduced.

It is important that treatments and procedures used by physiotherapists do not cause a further burden on the work of breathing, exposing the patient to an increased risk of respiratory distress.

We list below some of the most common practices used in respiratory physiotherapy that we do not recommended on patients with COVID-19 during the acute phase:

- diaphragmatic breathing;

- pursed lips breathing;

- bronchial hygiene/lung re-expansion techniques (PEP Bottle, EzPAP $^{\circledR}$, cough machines, etc.);

- incentive spirometer;

- manual mobilization/stretching of the rib cage;
- nasal washings;

- respiratory muscle training;

- exercise training;

- mobilization during clinical instability (multidisciplinary assessment required).

\section{$8^{\text {th }}$ ADVICE}

In order not to increase the work of breathing, it is necessary to limit bronchial hygiene techniques to limited cases, always taking into strong consideration the risk of contamination of the environment and providing appropriate PPE for health personnel.

\section{Measures for Prevention and Control of Infections}

Health personnel must pay particular attention during the interventions that may expose them to a higher risk of contamination due to dispersion of droplets in the air [22].

The highest risk procedures are:

- aerosol nebulization (if aerosol drugs administration is needed, try to use pre-dosed MDI)

- mucous clearance (Forced Expiratory Techniques, cough and other manoeuvres or devices such as a cough-assist machine promoting expectoration)

- NIV (in particular with systems that use open-masks or other open systems)

- bronchoscopy

- tracheal intubation

- manual ventilation before intubation

- tracheotomy

- endotracheal aspiration

- cardiopulmonary resuscitation

- extubation.

We recommend following the instructions given in the document produced by World Health Organization (WHO) $[23,24]$, or National Health Institutions in order to PPE use during the care of COVID-19 Patients. In Table 2 we list the main technical characteristics of disposable masks used during care of COVID-19 patients.

Table 1. Side effects and suggestion for pronation therapy.

COMPLCATIONS SOLUTIONS

Pressure ulcers

Facial / periorbital oedema

Corneal and/or conjunctiva damage

Brachial plexus injury

Poor positioning of the auricle

Venous access and catheter stability problems

Staff injury
Change of head and arm posture every 4-6 hours. Verify that the endotracheal tube is not pressed against the mouth/lips and that the gastric nose tube does not exert excessive pre sure against the nostril. Use adequate anti-decubitus equipment and protect the higher-pre sure areas, for example using high density or resilient foams Keep the bed in anti-Trendelenburg position at $30^{\circ}$. Clean and close eyelids and protect the eyes by applying ophthalmic ointment and a protective patch Practice correct positioning and modify upper limb postures.

Verify that the lower ear is not bent. Make sure the accesses are well fixed and do not exert excessive pressure on the skin. Correctly educate the operators and identify the appropriate number of healthcare practitioners involved in the prone position manoeuvre according to patient size and to the number of devices available. Correctly manage the devices and optimize staff coordination during the execution of the manoeuvre 
Table 2. Technical characteristics of disposable masks used during care of COVID-19 patients.

\begin{tabular}{|c|c|}
\hline Surgical mask & $\begin{array}{l}\text { - Limits the spread of potentially infectious particles by infected or } \\
\text { potentially infected individuals into the environment } \\
\text { - It has no filtering function in the inspiratory phase, therefore it does } \\
\text { not protect against inhalation of small particles (aerosols) } \\
\text { - It must be worn by infected or potentially infected individuals. }\end{array}$ \\
\hline FFP1 & $\begin{array}{l}\text { - Filters } 80 \% \text { of environmental particles with a diameter } \geq 0.6 \mu \mathrm{M} \\
\text { - If equipped with an expiratory valve, it has no filtering function in } \\
\text { the expiratory phase }\end{array}$ \\
\hline - It is not recommended for protection from airborne pathogens \\
\hline FFP2 & $\begin{array}{l}\text { - Filters } 95 \% \text { of environmental particles with a diameter } \geq 0.6 \mu \mathrm{M} \\
\text { - If equipped with an expiratory valve, it has no filtering function in } \\
\text { the expiratory phase (the expiratory valve is for operator comfort) }\end{array}$ \\
\hline - It must be worn by healthcare professionals assisting infected or \\
potentially infected individuals
\end{tabular}

\section{$9^{\text {th }}$ ADVICE}

In order to protect the health personnel tray to reduce unnecessary manoeuvres, particularly the procedures that can generate droplets/aerosol.

Apply droplet precautions:

- All patients should wear a surgical mask, also during HFNO treatment.

- Apply filters to CPAP/NIV circuit to reduce air contamination. Nevertheless, filters in the CPAP/NIV circuit can increase the work of breathing due to an increase circuit resistance in severely compromised patients, that's why it is important to monitor patient breathing pattern continuously.

- Verify with the team the best strategy to assist each patient but at the same time to protect the healthcare staff.

- Evaluate the use of Helmet instead of mask if you think the resistance of the circuit due to filters may increase the work of breathing of the patient.

\section{$10^{\text {th }}$ ADVICE}

Organize the working environment and the shifts in order to reduce the risk of contamination and to optimize the availability of PPE.

\section{Conclusions}

Patients affected with Covid-19 who need to be hospitalized present a viral pneumonia often complicated by an Acute Respiratory Failure that may eventually evolve to ARDS.

To face this emergency, entire hospitals wards have been transformed into ICU and HDU in order to host patients requiring ventilatory support. Properly trained staff is required in order to manage in an efficient way such units.
All healthcare workers have been reacting with incredible commitment and willingness and of course, physiotherapists are also being called to contribute.

In principle they are well trained to execute these tasks [25], ARIR (Italian Association of Respiratory Therapists), in collaboration with AIFI (Italian Association of Physiotherapists), issued this document to provide a quick respiratory physiotherapist reference guide to set up treatments for the management in acute stages of patients suffering from severe COVID-19.

The main goal of such treatments is to reduce side effects in this patients' population while maximally protection of healthcare professionals.

\section{References}

1. Lai CC, Shih TP, Ko WC, et al. Severe acute respiratory syndrome coronavirus 2 (SARS-CoV-2) and coronavirus disease2019 (COVID-19): The epidemic and the challenges. Int J Antimicrob Agents 2020;55:105924. doi: 10.1016/j.ijantimicag.2020.105924.

2. Wujtewicz M, Dylczyk-Sommer A, Aszkiełowicz A, et al. COVID-19 - what should anaethesiologists and intensivists know about it? Anaesthesiol Intensive Ther 2020. pii: 40133. doi: 10.5114/ait.2020.93756.

3. Kallet RH, Hemphill JC, Dicker RA, et al. The spontaneous breathing pattern and work of breathing of patients with acute respiratory distress syndrome and acute lung injury. Respir Care 2007;52:989-95.

4. Meng L, Qiu H, Wan L, et al. Intubation and ventilation amid the COVID-19 outbreak: Wuhan's Experience. Anesthesiology 2020. doi: 10.1097/ALN.0000000000003296. [Epub ahead of print]

5. Seto WH, Tsang D, Yung RW, et al. Effectiveness of precau- 
tions against droplets and contact in prevention of nosocomial transmission of severe acute respiratory syndrome (SARS). Lancet 20033;361:1519-20.

6. Ding L, Wang L, Ma W, He H. Efficacy and safety of early prone positioning combined with HFNC or NIV in moderate to severe ARDS: a multi-center prospective cohort study. Crit Care 2020;24:28. doi: 10.1186/s13054-020-2738-5

7. Zhou F, Yu T, Du R, et al. Clinical course and risk factors for mortality of adult inpatients with COVID-19 in Wuhan, China: a retrospective cohort study. Lancet 2020. pii: S01406736(20)30566-3. doi: 10.1016/S0140-6736(20)30566-3. [Epub ahead of print]

8. Hui DS, Chow BK, Chu L, et al. Exhaled air dispersion and removal is influenced by isolation room size and ventilation settings during oxygen delivery via nasal cannula. Respirology 2011;16:1005-13. doi: 10.1111/j.1440-1843.2011.01995.x

9. Hui DS, Chow BK, Chu LCY, et al. Exhaled air and aerosolized droplet dispersion during application of a jet nebulizer. Chest 2009;135:648-54. doi: 10.1378/chest.08-1998

10. Hui DS, Ip M, Tang JW, et al. Airflows around oxygen masks: A potential source of infection? Chest 2006;130:822-6.

11. Hui DS, Chan MT, Chow B. Aerosol dispersion during various respiratory therapies: a risk assessment model of nosocomial infection to health care workers. Hong Kong Med J 2014;20:S9-13.

12. Hui DS, Chow BK, Lo T, et al. Exhaled air dispersion during high-flow nasal cannula therapy versus CPAP different masks. Eur Respir J 2019;53. pii: 1802339. doi: 10.1183/13993003.02339-2018

13. Leung CCH, Joynt GM, Gomersall CD, et al. Comparison of high-flow nasal cannula versus oxygen face mask for environmental bacterial contamination in critically ill pneumonia patients: a randomized controlled crossover trial. J Hosp Infect 2019;101:84-7. doi: 10.1016/j.jhin.2018.10.007.

14. Writing Group for the Alveolar Recruitment for Acute Respiratory Distress Syndrome Trial (ART) Investigators, Cavalcanti AB, Suzumura ÉA, et al. Effect of Lung Recruitment and Titrated Positive End-Expiratory Pressure (PEEP) vs low PEEP on mortality in patients with acute respiratory distress syndrome: A randomized clinical trial. JAMA 2017;318:1335-45. doi: 10.1001/jama.2017.14171

15. Favretto DO, Silveira RC, Canini SR, et al. Endotracheal suction in intubated critically ill adult patients undergoing mechanical ventilation: a systematic review. Rev Lat Am Enfermagem 2012;20:997-1007.

16. Guérin C, Reignier J, Richard JC, et al. Prone positioning in severe acute respiratory distress syndrome. NEJM. 2013;368:2159-68.

17. Blackwood B, Alderdice F, Burns KE, et al. Protocolized versus nonprotocolized weaning for reducing the duration of mechanical ventilation in critically ill adult patients. Cochrane Database Syst Rev 2010;CD006904.

18. Peña-López Y, Ramirez-Estrada S , Eshwara VK, Rello J. Limiting ventilator-associated complications in ICU intubated subjects: strategies to prevent ventilator-associated events and improve outcomes. Expert Rev Respir Med 2018;12:1037-50.

19. Fan E. Critical illness neuromyopathy and the role of physical therapy and rehabilitation in critically ill patients. Respir Care 2012;57:933-44; discussion 944-6.

20. Van Aerde N, Meersseman P, Debaveye Y, et al. Five-year impact of ICU-acquired neuromuscular complications: a prospective, observational study. Intensive Care Med 2020 doi: 10.1007/s00134-020-05927-5. [Epub ahead of print]

21. Ambrosino N, Makhabah DN Comprehensive physiotherapy management in ARDS. Minerva Anestesiol 2013;79:554-63.

22. [Expert consensus on preventing nosocomial transmission during respiratory care for critically ill patients infected by 2019 novel coronavirus pneumonia].[Article in Chinese; Abstract available in Chinese from the publisher]. Zhonghua Jie He He Hu Xi Za Zhi 2020;17:E020. doi: 10.3760/cma.j.issn.10010939.2020.0020. [Epub ahead of print])

23. WHO. Clinical management of severe acute respiratory infection when novel coronavirus $(2019-\mathrm{nCoV})$ infection is suspected. Interim guidance. January 2020. Available from: https://www.who.int/publications-detail/clinical-managementof-severe-acute-respiratory-infection-when-novel-coronavirus-(ncov)-infection-is-suspected

24. WHO. Global surveillance for COVID-19 disease caused by human infection with the 2019 novel coronavirus. Interim guidance. February 2020. Available from: https://www.who.int/publications-detail/global-surveillancefor-human-infection-with-novel-coronavirus-(2019-ncov)

25. Troosters T, Langer D, Burtin C, et al. A guide for respiratory physiotherapy postgraduate education: presentation of the harmonised curriculum. Eur Respir J 2019;53. pii: 1900320. doi: 10.1183/13993003.00320-2019. 